\title{
Impact of Asking Support Questions on Grades 4 and 7 Students Reading Comprehension
}

\author{
Pilve Kängsepp \\ Department of General Education, Faculty of Social Science and Education, Tartu University, \\ Tartu, Estonia. \\ Email: pilve.kangsepp@mail.ee \\ Received August 14 ${ }^{\text {th }}, 2011$; revised September 18 ${ }^{\text {th }}, 2011$; accepted September $26^{\text {th }}, 2011$.
}

\begin{abstract}
This study investigated the effect of support questions and their timing on Grades 4 and 7 students' reading comprehension. The support questions were posed either during or after reading texts. A comparative analysis of students' scores in answering of control questions presented at the end of the reading assignment revealed that asking inferential support question has positive effect on the text comprehension only in certain conditions. The effect of inferential support questions is rather negative if the text to be read is difficult and support questions are posed after reading the text sections.
\end{abstract}

Keywords: Reading, Reading Comprehension, Question Timing, Questions

\section{Introduction}

Reading comprehension has been a part of classrooms as long as there have been schools, texts, students, who desire to read them, and teachers wanting to both promote and assess their understanding (Pearson, 2009). Students are working with texts for about $60 \%$ of the lesson time and most of their homework consists of studying texts (Johnsen, 1993). The comprehension of a text can range from the most superficial to deep understanding but the school learning requires a rather deep understanding of study texts (Kintsch, 1994). The majority of students comprehend study texts without difficulty but there are always some children for whom reading comprehension is a particularly difficult task (Spooner, Gathercole, \& Baddeley, 2006; Megherbi, Seigneuric, \& Ehrlich, 2006). Furthermore, Oakhill and Yuill (1996) pointed out that a reason for many students' learning difficulties is poor understanding of written texts.

A number of factors interfering with the development of students' text comprehension skill have been uncovered by researchers. These factors range from efficiency of decoding and catching meaning at the level of single words through syntactic development to inference making and integration of the ideas in the text as whole (Oakhill \& Cain, 2003). Yet, Nation and Angell (2006) pointed out that a greater part of difficulties in reading comprehension remain hidden and unnoticed by teachers.

Good text comprehension by students means that they integrate the text information with their previous knowledge and acquire new information. One possibility to support reading comprehension process might be answering questions.

The purpose of this study is to investigate the impact of support questions on text comprehension depending on students' grade, timing of support questions and text complexity.

\section{Text Comprehension}

In the theory of text comprehension of Van Dijk and Kintsch (1983; Kintsch, 1994) the process of reading with understanding is conceived as construction of semantic representations of the text (text-base model) and also as creating of more personal mental representations integrated with the reader's prior knowledge (situation model). The text-base level memory-based representations of the words and ideas are constructions as they appear in a text. The words and phrases themselves are encoded as linguistic relations between them. The text-base level of representation would include a propositional description of the explicit text (Kintsch \& Van Dijk, 1978), which means the text-base level understanding provides a shallow representation. In the situation model the information extracted from the text is elaborated from the prior personal knowledge and is integrated with it (Kintsch, 1994). This is why Van Dijk and Kintsch have distinguished text-base model from the situation model. When we read the text we do not perceive the individual sentences conveying isolated pieces of information. Rather, we perceive them as being interconnected, as forming a coherent whole. The perception of coherence is the result of extensive inferential processes, some of which are automatic while others are intentional and strategic. A representation results from extensive inferential processes that take place during reading (Van den Broek, Rohleder, \& Narvaez, 1994). In general, inference is a cognitive process used to construct meaning (Davoudi, 2005). Therefore, it is widely accepted by researchers that the ability to make inferences is necessary for reading comprehension (e.g., Oakhill \& Cain, 2003; Davoudi, 2005). Self-evidently, if the reader does not understand the text-base, the situation model will not be adequately constructed. In this case, the reader could be able to answer factual questions, but he or she is not capable to make inferences. Or, expressed in another way, students have a good understanding of textual material, when they have successfully integrated information from the text with their prior knowledge, and thus are able to learn the new material (Kozminsky \& Kozminsky, 2001).

Paris, Cross and Lipson (1984) showed that some students in elementary education seemed to have difficulty in understanding the relationship between evidences and conclusions and this may make it difficult to see how words can provide clues to meaning within text. Long, Oppy and Seely (1994) argued that if readers are unable to generate inferences that connect explicit information in a text to relevant prior knowledge, they feel as 
though they do not comprehend the text and have difficulty remembering it. They are often able to integrate information at the level of single sentences but are unable to produce a coherent integrated model of the text as whole (Mannes \& Kintsch, 1987). This is because poor readers have difficulties with making inferences and these difficulties are likely a cause of their understanding of texts at a low level of generalization (Cain \& Oakhill, 1999; Perfetty, Landi, \& Oakhill, 2005).

A deeper comprehension is achieved when the reader constructs causes and motives that explain why an event or action occurred, by inferring the global message or point of the text, and by relating the state of affairs or situation described in the text to the state of affairs in the world which is located in the background knowledge structure of the reader of the text. A deeper comprehension means that the reader constructs more levels of representations and makes more inferences than it is possible reading at the text-base level only (Davoudi, 2005). Consequently, if the aim is improving the reader's text comprehension, it is necessary to challenge him or her to construct representations and make inferences of this text. Sundbye (1987) found that asking inferential questions about relationships between characters in a text, their goals and motivations for action, enhanced children's comprehension as effectively as modifying the text to be more explicit. Inferential questions call for a more thorough and systematic processing of a text and prompt the integration of text-based concepts with a broader background knowledge, which may enhance children's understanding of a text (McGee \& Johnson, 2003). This means that asking of inferential questions may be a helpful tool in supporting students' reading with understanding.

\section{Using Questioning for Increasing Text Comprehension}

Many studies refer to an opportunity of increasing children's reading with understanding by having them to answer questions pertaining to the text to be learned (Anderson \& Biddle, 1975; Pressley et al., 1989; Cerdan et al., 2009). According to Olson, Duffy, and Mack (1985) answering of these questions can be considered as an indicator of understanding the text to be read, but posing of questions can also serve as an advance organizers of meaning (Ausubel, 1968) in further reading of the text. Questions support the construction of a causal network representation, resulting in better understanding of a text as a whole. This suggests that asking the reader some questions while reading a text might be an effective tool for guiding his or her understanding of the text. For example, Van den Broek et al. (2001) showed that posing supportive questions during reading helps understanding of the text. Answering questions pertaining to the text to be read enhances learning from it (Pressley et al., 1989) because the questions challenge the reader to find relations between queried and answered information and focus the reader's attention on moments necessary for comprehending the text (Olson, Duffy, \& Mack, 1985). However, the positive effect of asking support questions does not appear unconditionally. It is the most effective if it really helps a reader to focus on finding relations between perceived and resulting information that he or she is expected to have as a prove of comprehending the read text. In certain cases asking of support questions may cause cognitive overload of student short term memory and be ineffective (Kirschner, 2002). One among many factors that would impact the readers' information processing capabilities is timing of support questions (Van den Broek et al., 2001). For example, if finding answers to support questions causes cogni- tive overload during reading, it barely supports understanding.

Therefore, the timing of questions for supporting text comprehension in reading has caught attention of many researchers (see Anderson \& Biddle, 1975; Pressley et al., 1989; Van den Broek et al., 2001). Questions can be asked before, during and after reading the text. Questioning after reading the entire text generally increases text comprehension in adults (Anderson \& Biddle, 1975) and helps only if questions lead to reprocessing of relevant information after the reader fails to answer an after text question. Pressley et al. (1989) showed that younger students are unable to look back for finding answers to after text questions that they could not answer directly. This failure is common to elementary school children and poor readers even in upper elementary school (Pressley et al., 1989).

Van den Broek et al. (2001) demonstrated that questions that were presented during reading helped the older students to memorize information targeted by the questions. The same effect was not documented with younger students. The explanation is in the light of the notion of cognitive overload that questioning during reading calls for a simultaneous processing of general information drawn from the text and of specific information targeted by the questions. Due to their poor reading skills, younger readers fail to implement these two tasks simultaneously, and presenting of inferential questions asked during reading rather interferes with their text comprehension than supports it. This means that not all ways of questioning are helpful for reading comprehension, a conclusion that is confirmed by conflicting results of former research (see e.g. Anderson \& Biddle, 1975; Pressley et al., 1989; Van den Broek et al., 2001; Cerdan et al., 2009).

The specific aim of this study is to investigate the impact of support questions on academic text comprehension in Estonian language depending on students' grade level and timing of questions in classroom. The research questions of this study were the following. First, how timing of inferential support questions influences reading comprehension depending on the age of readers; second, how does the impact of support inferential questions depend on text complexity in Estonian conditionsns.

\section{Methods}

\section{Participants and Procedure}

This study was carried out in Estonian comprehensive school consisting of students from schools willing to co-operate. The study was conducted in the beginning of the school year, with students who had completed Grade 3 and 6, and started a new school level (Grade 4 and 7, respectively). 274 students participated in the first phase and 294 in the second phase of this study (Table 1). There were 131 boys and 111 girls among the Grade 4 students, and 157 boys and 169 girls in Grades 7. The students' average age in Grade 4 was 10.5 years and in the Grade 713.4 years. All of them were native Estonian language speakers.

The impact of asking support questions on student reading comprehension was tested on the basis of two texts with different readability indices in both grades. In the phase one, carried out in 2007/08, a rather easy readable text, and in phase two, in 2008/09 school year, a more difficult text was used for testing.

In the both research phases participants were divided (at random basis) into three groups at each grade level-experimental group 1 and experimental group 2 and a control group. 
Table 1.

The distributions of students by grades and groups.

\begin{tabular}{cccccc}
\hline & \multicolumn{2}{c}{ Phase I } & \multicolumn{2}{c}{ Phase II } & In All \\
\cline { 2 - 5 } & Grade 4 & Grade 7 & Grade 4 & Grade 7 & \\
\hline $\begin{array}{c}\text { Experimental } \\
\text { group I }\end{array}$ & 37 & 52 & 42 & 53 & 184 \\
$\begin{array}{c}\text { Experimental } \\
\text { group II }\end{array}$ & 36 & 57 & 43 & 58 & 194 \\
$\begin{array}{c}\text { Control group } \\
\text { In all }\end{array}$ & 42 & 50 & 42 & 56 & 190 \\
\hline
\end{tabular}

The experimental and control groups received their text booklets and after the reading the instruction participants progressed through the booklets at their own pace according to the instruction. The students in the experimental groups were asked to read the text in two different conditions, and to answer control questions for testing their understanding afterwards. In the experimental group 1 the comprehension of the text was supported by asking inferential support questions after reading the text just before answering the control questions. In the experimental group 2 the support questions were posed during reading the text after reading through its sections. The students in the control group answered control questions after reading the text.

\section{Characterization of Text and Measurements}

A story titled "Catching words" written by H. Veigel from third grade textbook was adapted for appropriate for phase one of this study. This is an expository text about invention of the recorded messages. A readability index of the text ${ }^{1}$ was 13.0 (easy readable text) that is within powers of Grade 3 students according to the established criteria of optimality for the Estonian readability index (Mikk, 2000). The text is 27 sentences long and its average length of sentences is 10 words.

For the phase two a story about insect life on the earth, written by U. Tartes, also from third grade textbook but with the readability index 15.0 (hard readable text), was selected. This text is 38 sentences long and its average length of sentences is 12 words.

The readability indices of potential texts in this study were determined using Mikk's (2000) readability formula. The text complicacy index includes independent sentence length in letter spaces and abstractness of repeating nouns in the text passage according to three scale. Total frequency of text's words according to the list of known words divided by the number of text's words (Mikk, 2000).

All materials necessary for investigating reading comprehension of experimental and control groups were delivered to students in special booklets. Three different versions of booklets were constructed for presenting support questions to experimental groups and for presenting control questions in each phase of the study. The control questions were located overleaf in regard of texts to be read in order to prevent consulting the text when answering the questions.

In the both phases of the study five support questions and the same number of control questions were used. The decision for using five inferential support and control questions was based on the analysis of texts by a triad of primary school teachers

${ }^{1}$ Readability index is an index of text complicacy while higher values of readability index show that the text is less readable (Mikk, 2000). who came to a consensual agreement that the both texts contain five paragraphs that could considered as logical entities. The preliminary sets of support and control questions were also compiled by the same team of teachers. To this end they first recorded all possible questions pertaining to these texts. Then selected by teachers on consensual basis the most suitable versions for support and control questions. The consensus was of at least $92 \%$.

Answers to support and control questions were scored on binary scale by assigning each correctly answered question one point and incorrectly answered questions zero point. Keeping in mind that the answers to inferential support questions might have interpretative character; a scoring guide was compiled with prototypes of correct answers. In total a student could obtain 5 points maximum for the correctly answered support questions as well as for answering the control questions. Next, the obtained data, including quantified demographic data of students were tabulated and processed using methods of descriptive and inferential statistics.

\section{Results}

\section{Comparison of Mean Scores in Answering Control Questions}

The mean scores of the experimental and the control groups in answering the control questions in Grades 4 and 7 are given in Table 2 for the phase one and in Table 3 for the phase two of the study. The comparison of the mean scores of the control questions in phase one shows that in the experimental groups of Grade 4 there was no statistical significant difference found between the groups. Yet, in the experimental groups of Grade 7 the exposure to the support questions caused a statistically significant increase in reading comprehension in comparison with the control group. In the experimental condition one when the support questions were presented after reading the text, the average scores of answering control questions was 2.9 but in the experimental condition two when the support questions were posed during reading, the mean score in answering the ontrol questions was 2.8 in the control group was 2.2 (Table 2).

In the phase two of the study the mean scores of answering the control questions in the control groups (2.0 and 2.5) were higher than in the experimental groups at the both grade levels. The differences were statistically significant. It means that answering of inferential support questions, independently on timing, aggravated comprehension of the text with higher readability index (Table 3).

\section{Comparison of Mean Scores of Experimental Groups in Answering of Inferential Support Questions}

The mean scores in answering the support questions by experimental groups in phases one and two of the study are presented in Table 4. As can be seen from the table, the average scores in answering the support questions were statistically significantly lower in the phase two than in the phase one for the both experimental conditions. The differences in scores were the biggest for the experimental condition one $(0.9$ for Grade 4 and 1.4 for Grade 7) when the support questions were posed after reading the text. The significantly lower scores in answering the support questions in the phase two (when a text with a higher readability index was used) confirm that the students had more difficulties in answering support questions in this case than in the phase one. 
Table 2 .

Comparison of mean scores in answering control questions by experimental and control groups in phase one (easy readable text).

\begin{tabular}{|c|c|c|c|c|c|c|c|}
\hline \multirow{2}{*}{ Grade } & \multirow{2}{*}{$\begin{array}{c}\text { Control Group } \\
\text { Mean }\left(\mathrm{SD}^{*}\right)\end{array}$} & \multicolumn{3}{|c|}{ Experimental Group I (Support Questions After Reading) } & \multicolumn{3}{|c|}{ Experimental Group II (Support Questions During Reading) } \\
\hline & & Mean (SD) & Diff** & $\mathrm{p}$ & Mean (SD) & Diff & $\mathrm{p}$ \\
\hline 7 & $2.2(1.3)$ & $2.9(1.3)$ & 0.7 & $<0.02$ & $2.8(1.4)$ & 0.6 & $<0.02$ \\
\hline
\end{tabular}

*SD—Standard deviation; **Diff—Difference with the mean score of the control group.

Table 3.

Comparison of mean scores in answering control questions by experimental and control groups in phase two (hard readable text).

\begin{tabular}{|c|c|c|c|c|c|c|c|}
\hline \multirow{2}{*}{ Grade } & \multirow{2}{*}{$\begin{array}{c}\text { Control Group } \\
\text { Mean }\left(\mathrm{SD}^{*}\right)\end{array}$} & \multicolumn{3}{|c|}{ Experimental Group I (Support Questions After Reading) } & \multicolumn{3}{|c|}{ Experimental Group II (Support Questions During Reading) } \\
\hline & & Mean (SD) & Diff** & $\mathrm{p}$ & Mean (SD) & Diff & $\mathrm{p}$ \\
\hline 4 & $2.0(1.0)$ & $1.6(0.8)$ & -0.4 & $<0.03$ & $1.4(1.0)$ & -0.6 & $<0.00$ \\
\hline 7 & $2.5(1.1)$ & $2.0(1.2)$ & -0.5 & $<0.04$ & $2.2(1.0)$ & -0.3 & $<0.06$ \\
\hline
\end{tabular}

*SD—Standard deviation; **Diff—Difference with the mean score of the control group.

Table 4.

Comparison of differences in mean scores of experimental groups in answering support questions in the phases one and two.

\begin{tabular}{|c|c|c|c|c|c|c|c|c|}
\hline \multirow{2}{*}{ Grade } & \multicolumn{4}{|c|}{ Experimental Condition I (Support Questions after Reading) } & \multicolumn{4}{|c|}{ Experimental Condition II (Support Questions during Reading) } \\
\hline & Mean Phase I & Mean Phase II & Diff & $\mathrm{p}$ & Mean Phase I & Mean Phase II & Diff & $\mathrm{p}$ \\
\hline 7 & 4.4 & 3.0 & 1.4 & $<0.04$ & 4.4 & 3.4 & 0.4 & $<0.05$ \\
\hline
\end{tabular}

The comparison of mean scores in answering support questions at different timing conditions revealed no dependence on timing of support questions in the phase one of the study (Table 5 ). The difference in mean scores does not surpass 0.1 points. Instead, in the phase two where a more difficult text with higher readability index was used, the students tended to produce better result in answering support questions when they were presented during reading the text. In Grade 4 the difference was 0.3 points (not statistically significant) and in Grade 7 the difference was 0.4 point that is statistically significant $(p<0.02)$.

\section{Correlation Answering Control and Support Questions}

The correlations between average scores of answering support questions and control questions for the phase one in Grade 4 and 7 were $r=0.34$ and $r=0.47$ (when support questions asked after reading) and $\mathrm{r}=0.48$ and $\mathrm{r}=0.60$ (when support questions asked during reading), see Table 6 .

The relationships between average scores of answers given to support and control questions for the phase two of the study in Grade 4 and 7 were $r=0.33$ and $r=0.32$ (when questions asked after reading), and $\mathrm{r}=0.47$ and $\mathrm{r}=0.16$ (when questions asked during reading). All values are statistically significant except 0.16 .

\section{Discussion}

Our comparative analysis of students' scores in answering of control questions taken as indicators of comprehension of texts to be read reveals that the impact of asking inferential support questions depends on the reading proficiency (correlating with the age of students in general) and on the timing (i.e. asked questions during or after reading) of these questions. The effect was stronger in the phase one when an easy readable text (optimal for Grade 3 level students) was used. However, even in this condition, the impact of inferential support questions depends on the students' grade level as well as on the timing of support questions. Asking inferential support questions improved students' comprehension of the text in Grade 7 independently on the timing of support questions. Instead, the exposure of Grade 4 students to inferential support question did not show significant differences in reading comprehension between control and experimental groups. However, it can be said with certain reservation that inferential support questions posed after reading had a rather positive effect on text comprehension.

When a text with a higher readability index was used in the phase two of the study, asking of support questions did not have any positive effect on the text comprehension at either grade levels. Instead, the mean scores in answering control questions were significantly lower at both grade levels. Furthermore, the higher scores of the control groups in answering control question in comparison with the experimental groups at both grade levels points to the fact that answering of inferential questions rather interfered with remembering of essential information. It occasionally caused a kind of cognitive overload in students or distracted them from remembering factual information. The explanation might be that answering of support questions during reading may overload the young readers' working memory because they have to deal simultaneously with their normal reading processes and with answering the questions. Questions posed after reading also tax young read- 
Table 5 .

Comparison of mean scores of experimental groups in answering support questions within the phases one and two.

\begin{tabular}{cccccccccc}
\hline \multirow{2}{*}{ Grade } & \multicolumn{4}{c}{ Phase I } & \multicolumn{3}{c}{ Phase II } \\
\cline { 2 - 9 } & Mean Exp C I* & Mean Exp C II** & Diff & $\mathrm{p}$ & Mean Exp C I & Mean Exp C II & Diff & p \\
\hline 4 & 4.0 & 3.9 & 0.1 & $>0.05$ & 3.1 & 3.4 & -0.3 & $>0.05$ \\
7 & 4.4 & 4.4 & 0.0 & $>0.05$ & 3.4 & 3.8 & -0.4 & $<0.02$ \\
\hline
\end{tabular}

*Exp C I stands for "Experimental condition I (support questions presented after reading)"; **Exp C II stands for "Experimental condition II (support questions presented during reading)".

Table 6.

Correlations between scores of answering inferential support and control questions by grade levels, research phases, and research conditions.

\begin{tabular}{ccccc}
\hline \multirow{2}{*}{ Grade } & \multicolumn{2}{c}{ Phase I } & \multicolumn{2}{c}{ Phase II } \\
\cline { 2 - 5 } & Exp C I* & Exp C II** & Exp C I & Exp C II \\
\hline 4 & 0.34 & 0.48 & 0.33 & 0.47 \\
7 & 0.47 & 0.60 & 0.32 & $0.16^{* * *}$ \\
\hline
\end{tabular}

*Exp C I stands for "Experimental condition I (support questions presented after reading)"; **Exp C II stands for "Experimental condition II (support questions presented during reading)"; ***All values in Table 6 , except 0.16 , are statistically significant at $\mathrm{p}<0.05$.

ers' ability to construct a coherent representation, but such effect is weaker than that of questioning during reading (Van den Broek et al., 2001).

Though the only clearly documented factor that might eliminate the positive impact of support questions on reading comprehension in the phase two was using of a text that was more difficult to read and understand, other factors like students' familiarity with text topics or dependence on the nature of support and control questions cannot be ruled out either. For example, the topic of the text used in phase one could be more familiar to the students than that used in phase two. Van den Broek et al. (2001) also pointed out that questioning might interfere even with skilled readers' comprehension if the reading task is highly demanding, for example when the content or structure of the text is complicated or unfamiliar to reader.

It also cannot be ignored that in the phase two not only the readability index of the used text was higher, but also this text was longer ( 38 sentences) than that used in phase one (27 sentences). The fact that this text called for higher reading and memorizing skills was also corroborated by a lower mean score in answering control questions by the total research sample in comparison with phase one. The same conclusion can be made from the fact that negative and significant correlations of scores in answering support and control questions with the phase number of the study were uncovered. Also, when calculated separately for grade levels, the mean score for Grade 7 in phase one was significantly higher than in phase two. However, the difference was less than half point. A comparison of mean scores in answering of support questions between two phases shows that these scores are significantly higher in the both experimental conditions for phase one. At the same time only one relevant difference in the mean scores in answering support questions caused by their timing was uncovered at Grade 7 level for phase two i.e. the students had higher scores in answering the support questions when they were posed during reading although the difference was also here less than a half point.
Quite informative are correlations found between scores in answering support and control questions. The fact that the correlation was significantly higher for the phase one than for the phase two confirms that there was less impact of answering support questions on answering control questions. This conclusion is also supported by differences of correlations that are calculated separately for Grades 4 and 7 for the both phases of the study. In the phase one when the text was more within powers of Grade 4, the correlations in answering these two types of questions for Grades 4 and 7 were almost equal. In the phase two the correlation was still statistically significant for the Grades 4 and 7. A more detailed analysis of the last mentioned correlation revealed that in the experimental condition one this correlation was for Grade 7 but was insignificant for the condition two (when the support questions were asked during reading).

A low correlation between scores of answering support and control questions in phase two at Grade 7 level in comparison with phase one points to the fact that there is practically no impact of support questions on the comprehension of the entire text when the support questions are presented during reading the text. Furthermore, the difference between the means correlation quotients is statistically significant. A possible explanation for this situation is that the text used in phase two was not only beyond powers of Grade 4 students but also of Grade 7 students.

However teachers should be careful in using support questions until students reach an adequate level of reading proficiency (see also Seretny \& Dean, 1986; Tal, Siegel \& Maraun, 1994; Van den Broek et al., 2001). Since teachers mostly rely on short-answer or completion test items in their everyday work with students than use questions that require answering with phrases or complete sentences it is possible that they do not even notice that the text as a whole is not understood by the students. Thus, the reading comprehension difficulties remain unnoticed as Nation and Angell (2006) have pointed out.

Yet, the teachers must teach students to learn textual information by relating it to something they already know. Some students do not understand how to construct the answer from prior knowledge and textual content. Thus, asking inferential support questions may become a powerful tool in promoting children' text-related activities. Answering to inferential support questions imposes a more thorough and systematic processing of text and prompt the integration of text-base concepts with background knowledge, which may enhance children's comprehension of a text. Poor readers may need a systematic training in such skills (McGee \& Johnson, 2003; Davoudi, 2005).

These conclusions should be taken with some precaution because of some limitations of this study. For making them more reliable new studies are needed that take the characteristics of the texts (in terms of familiarity to students and length) with different readability indices better under control. Also, experi- 
mentation with students in other elementary grades could be beneficial for more reliable conclusions on the effect of answering inferential support questions on promoting reading skills. The limitations in tests (no normative test only teachers choices of questions, no memory test, no vocabulary test, no fluency test); possible floor effect and ceiling effect of scores, and the limitations of the analysis that no predictive relationships can not be said. So the results remain in descriptive level but they give some important aspects to study questioning in comprehension in the future.

\section{Conclusion}

In summary asking inferential support questions has positive effect on the text comprehension only in certain conditions. The impact of support questions depends on the students' grade level as well as on the timing of support questions. Our findings also suggest that asking of support questions can be used for directing the attention to specific information and to prompt to specific connection. The outcomes of this study have practical implications for elementary grade teaching of reading comprehension skills by using support questions. Especially, these outcomes might be helpful in providing texts (study aids) used for exercising reading comprehension with inferential support questions. When preparing these assignments, the combined impact of the both factors - readability of the underlying text and timing of inferential support questions - must be taken into account. When using an easy readable text answering of inferential support questions promotes text comprehension rather independently of their timing. In the case of texts that are harder to read but still within the power of students, inferential questions that are posed after reading might more effective for promoting reading comprehension. When the text is clearly beyond the capabilities of students, answering of inferential support questions generally has no positive effect on text comprehension and corresponding reading assignments can barely promote students' skills of reading with understanding.

\section{Acknowledgements}

The author thanks Edgar Krull for his comments and advice in preparation of the article.

\section{References}

Anderson, R., \& Biddle, W. (1975). On asking people questions about what they are reading. In G. H. Bower (Ed.), The Psychology of Learning and Motivation, (pp. 90-132). New York: Academic Press. doi:10.1016/S0079-7421(08)60269-8

Ausubel, D. (1968). Educational psychology: A cognitive view. New York: Holt, Rinehart \& Winston.

Cain, K., \& Oakhill, J. V. (1999). Inference making ability and its relation to comprehension failure in young children. Reading \& Writing: An Interdisciplinary Journal, 11, 489-503.

Cerdan, R., Vidal-Abarca, E., Martinez, T., Gilabert, R., \& Gil, L. (2009). Impact of question-answering task on search processes and reading comprehension. Learning and Instruction, 19, 13-27. doi:10.1016/j.learninstruc.2007.12.003

Davoudi, M. (2005). Inference generation skill and text comprehension. The Reading Matrix, 5, 106-126.

Johnsen, E. B. (1993). Textbooks in the kaleidoscope. A critical survey of literature and research on educational texts (pp. 165-166). Oslo: Scandinavian University Press.

Kintsch, W. (1994). Comprehension, memory and learning. American
Psychologist, 4, 294-303 doi:10.1037/0003-066X.49.4.294

Kintsch, W., \& Van Dijk, T. A. (1978). Toward a theory of automatic information processing in reading. Cognitive Psychology, 6, 294-323.

Kirschner, P. A. (2002). Cognitive load theory: Implications of cognitive load theory on the design of learning. Learning and Instruction, 12, $1-10$. doi:10.1016/S0959-4752(01)00014-7

Kozminsky, E., \& Kozminsky, L. (2001). How do general knowledge and reading strategies ability relate to reading comprehension of high school students at different educational levels. Journal of Research in Reading, 24, 187-204. doi:10.1111/1467-9817.00141

Long, D. L., Oppy, B. J., \& Seely, M. R. (1994). Individual differences in the time course of inferential processing. Journal of Experimental Psychology: Learning Memory and Cognition, 20, 1456-1470. doi:10.1037/0278-7393.20.6.1456

Mannes, S., \& Kintsch, W. (1987). Knowledge organisation and text organisation. Cognition and Instruction, 4, 91-115. doi:10.1207/s1532690xci0402_2

Megherbi, H., Seigneuric, A., \& Ehrlich, M. F. (2006). Reading comprehension in French 1st and 2nd grade children: Contribution of decoding and language comprehension. European Journal of Psychology of Education, 21, 135-147. doi:10.1007/BF03173573

Mikk, J. (2000). Textbook: Research and writing. Frankfurt am Main: Peter Lang.

Nation, K., \& Angell, P. (2006). Learning to read and learning to comprehend. London Review of Education, 4, 77-87. doi:10.1080/13603110600574538

Oakhill, J., \& Yuill, N. (1996). Higher order factors in comprehension disability: Processes and remediation. In J. C. Cornoldi and J. Oakhill (Eds.), Reading Comprehension Difficulties. Processes and Intervention (pp. 69-92). Mahwah, New Jersey: Erlbaum.

Oakhill, J. V., \& Cain, K. (2003). The development of comprehension skills. In P. Bryant (Ed.), Handbook of Children's Literacy (pp. 155180). The Netherlands: Kluwer Academic Publisher.

Olson, G. M., Duffy, S. A., \& Mack, R. L. (1985). Questions-asking as a component of text comprehension. In A. C. Graesser and J. B. Black (Eds.), The Psychology of Questions (pp. 219-226). Mahwah, New Jersey: Erlbaum.

Paris, S. G., Cross, D. R., \& Lipson, M. Y. (1984). Informed strategies for learning: A program to improve children's awareness and comprehension. Journal of Educational Psychology, 76, 1239-1252. doi:10.1037/0022-0663.76.6.1239

Pearson, P. D. (2009). The roots of reading comprehension instruction. In S. E. Israel and G. G. Duffy (Eds.), Handbook of Research on Reading Comprehension (pp. 3-31). New York: Routledge.

Perfetty, C. A., Landi, N., \& Oakhill, J. (2005). The acquisition of reading comprehension skill. In M. J. Snowling and C. Hulme (Eds.), The Science of Reading: A Handbook (pp. 227-253). Oxford, UK: Blackwell. doi:10.1002/9780470757642.ch13

Pressley, M., Johnson, C. J., Symons, S., McGoldrick, J. A., \& Kurita, J. A. (1989). Strategies that improve children's memory and comprehension of text. The Elementary School Journal, 90, 3-32. doi:10.1086/461599

Seretny, M. L., \& Dean, R. S. (1986). Interspersed post passage question and reading comprehension achievement. Journal of Educational Psychology, 78, 228-229. doi:10.1037/0022-0663.78.3.228

Spooner, A. L. R., Gathercole, S. E., \& Baddeley, A. D. (2006). Does weak reading comprehension reflect an integration deficit? Journal of Research in Reading, 29, 173-193. doi:10.1111/j.1467-9817.2006.00284.x

Sundbye, N. (1987). Text explicitness and inferential questioning: Effect of story understanding and recall. Reading Research Quarterly, 22, 82-98. doi: $10.2307 / 747722$

Tal, N. F., Siegel, L. S., \& Maraun, M. (1994). Reading comprehension: The role of question type and reading ability. Reading and Writing, 6, 387-402. doi:10.1007/BF01028850

Van den Broek, P., Rohleder, L., \& Narvaez, D. (1994). Cognitive processes in the comprehension of literary texts. In H. van Oostendorp and R. Zwaan (Eds.), Naturalistic Text Comprehension (pp. 229- 246). Norwood, New Jersey: Ablex Publishing Corp. 
Van den Broek, P., Tzeng, Y., Risden, K., \& Trabasso, T. (2001). Inferential questioning: Effect on comprehension of narrative text as a function of grade and timing. Journal of Educational Psychology, 9,
521-529. doi:10.1037/0022-0663.93.3.521

Van Dijk, T. A., \& Kintsch, W. (1983). Strategies of discourse comprehension. New York: Academic Press. 